\title{
A dynamic evaluation technique for assessing gas output from coal seams during commingling production within a coalbed methane well: a case study from the Qinshui Basin
}

\author{
Chuan $\mathrm{Wu}^{1,2,3} \cdot$ Chengxiang Yuan $^{1,2} \cdot$ Guojun Wen ${ }^{1,2}$ (1) Lei Han ${ }^{1,2} \cdot$ \\ Haojie Liu ${ }^{1,2}$
}

Received: 11 July 2019/Revised: 26 November 2019/Accepted: 26 December 2019/Published online: 29 January 2020

(C) The Author(s) 2020

\begin{abstract}
Gas drainage is carried out based on output from each coal bed throughout commingling production of coalbed methane $(\mathrm{CBM})$. A reasonable drainage process should therefore initially guarantee main coal bed production and then enhance gas output from other beds. Permanent damage can result if this is not the case, especially with regard to fracture development in the main gas-producing coal bed and can greatly reduce single well output. Current theoretical models and measuring devices are inapplicable to commingled CBM drainage, however, and so large errors in predictive models cannot always be avoided. The most effective currently available method involves directly measuring gas output from each coal bed as well as determining the dominant gas-producing unit. A dynamic evaluation technique for gas output from each coal bed during commingling CBM production is therefore proposed in this study. This technique comprises a downhole measurement system combined with a theoretical calculation model. Gas output parameters (i.e., gas-phase flow rate, temperature, pressure) are measured in this approach via a downhole measurement system; substituting these parameters into a deduced theoretical calculation model then means that gas output from each seam can be calculated to determine the main gas-producing unit. Trends in gas output from a single well or each seam can therefore be predicted. The laboratory and field test results presented here demonstrate that calculation errors in CBM outputs can be controlled within a margin of $15 \%$ and therefore conform with field use requirements.
\end{abstract}

Keywords Commingling production · Gas output - Dynamic evaluation · Coalbed methane - Qinshui Basin

Guojun Wen

wenguojun@cug.edu.cn

Chuan $\mathrm{Wu}$

wuchuan@cug.edu.cn

1 School of Mechanical and Electronic Information, China University of Geosciences (Wuhan), Wuhan 430074, China

2 Hubei Intelligent Geological Equipment Engineering Technology Research Center, Wuhan 430074, China

3 Key Laboratory of Tectonics and Petroleum Resources (China University of Geosciences) Ministry of Education, Wuhan 430074, China

\section{Introduction}

China boasts rich domestic natural gas reserves, including coalbed methane (CBM), and produced 138.4 billion cubic meters up until 2016 (Tao et al. 2019a). Deposits of CBM buried below $2000 \mathrm{~m}$ are known to cover an area of $29.8 \mathrm{~m}^{3}$ nationally (Tao et al. 2019b) and demonstrate that China has now entered early stage large-scale development of this resource (Qin et al. 2018). The Chinese government has accelerated research and development on CBM extraction technologies in recent years in order to make best use of these resources ( $\mathrm{Li}$ et al. 2015), especially in commingled drainage and extraction (Zhang et al. 2018a, b).

As interlayer interference can seriously limit highly efficient joint development in commingling CBM production (Tao et al. 2019b), it is necessary to determine field gas 
drainage and extraction processes based on coal bed gas output analyses. Thus, in order to guarantee gas output from a main coal bed, reasonable gas drainage and extraction processes should be employed to maximally enhance gas outputs from other coal beds as well as from a single well. At the same time, unreasonable gas drainage and extraction processes can also cause permanent damage to main gas-producing coal bed fracture development. This is important because fracture development plays a key role in all aspects of coal development and utilization (Chen et al. 2018; Liu et al. 2018); as a result, the main gasproducing coal bed will no longer yield this resource when fracture development is damaged and therefore greatly reduces single well output. The dominant gas-producing coal bed is of great significance for gas production within a single well and therefore must be monitored dynamically so that it can be determined. Numerous researchers globally have outlined the results of theoretical studies, including the Weng Cycle Prediction Model, the T Prediction Model (Min and Hu 1997), the Grey Prediction Model (Liu et al. 2014), the History Matching Degree Calculation Method (Glegola et al. 2012), and the Permeability Method (Ali and Sheng 2015). It is clear that existing theoretical calculation-based models all share a number of issues, including that:

(1) They are applicable to the total gas output of a single well but are unable to predict the specific gas output of a single coal bed;

(2) They are unable to dynamically predict the gas production distribution of each coal bed within a certain time period, and;

(3) They can generate large calculation errors.

This analysis shows that the most direct and effective available method is to directly measure gas output parameters from each coal seam, obtain the specific output from each by analyzing results, and then to finally determine the main gas-producing coal bed. There are currently two main forms of technologies and devices which can be used to realize real-time detection of downhole operating parameters.

(1) Pressure, temperature, and wellhead flow measurements

A number of international companies including Burlington, Halliburton, and River have developed automatic CBM extraction systems which collect real-time downhole pressure, temperature, and wellhead flow data. These systems can be used to adjust drainage and extraction parameters based on measured parameters (Anna 2003; Clarkson et al. 2007; Robertson et al. 2002). The PR300 Downhole Memory Electronic Pressure Gauge produced by WTS company, in particular, can be used to detect downhole pressure (Chen 2013), while the SentinelDTS distributed temperature measurement system produced by Sensornet can be used to detect and display these values in real time at different depths using optical fibers (Aminossadati et al. 2010).

\section{(2) Dynamic liquid level height measurements}

Pioneer Natural Resources have used a downhole successional pressure gauge to detect dynamic liquid level height values (Rotramel and Bell 2011). In this context, McCoy et al. (2009) proposed the use of a new technology approach based on the use of an acoustic sensor to measure dynamic liquid level heights in CBM wells. These workers also expounded this specific measurement method as well as calculation models based on this technology (McCoy et al. 2009). In a similar study, Budenkov et al. (2003a) also proposed a device that can detect liquid level hole height in CBM extraction wells using an acoustic sensor (Budenkov et al. 2003a, b), while Chen et al. (2009) used a downhole optical fiber to monitor dynamic liquid level height in real time (Chen et al. 2009). Similarly, Wu et al. (2018) also designed a working level CBM sensor that can be used to measure dynamic liquid level height ( $\mathrm{Wu}$ et al. 2018).

Existing detection devices are barely able to calculate CBM gas outputs for a number of reasons:

(1) Existing detection devices are only able to measure simple or small amounts of data and are unable to use existing measurement parameters to calculate gas outputs from each coal seam;

(2) Existing detection devices are unable to measure downhole gas-phase flow velocities even though these play an important role in gas output calculations from each coal seam, and;

(3) Parameters measured by detection devices are irrelevant overall because gas outputs from each coal seam cannot be obtained via coupling analyses or calculations.

This paper proposes a dynamic evaluation technique for each coal bed gas output during commingling CBM well production. This technique comprises a downhole measurement system coupled with a theoretical calculation model. Real-time measurements of gas output parameters (including gas-phase flow rate, temperature, and pressure) for different coal beds can be realized using a downhole measurement system. Substituting measured parameters into a deduced theoretical calculation model means that the gas output of each coal seam can be obtained and then the dominant gas-producing coal seam can be determined. This technique can also be used to calculate unit-thickness gas output as well as to predict gas output trends from each coal seam. 


\section{Theoretical calculation model of gas output}

Gas-liquid two-phase flow exists in CBM extraction wells irrespective of gas-liquid-solid three-phase flow due to the existence of coal dust (Ma et al. 2017). This means that parameters related to two-phase flow remains key to calculating CBM outputs (Wu et al. 2016). This means that gas outputs from each coal seam can be calculated by establishing a model for these volumes from commingled CBM drainage and extraction wells.

\subsection{Gas output calculations}

Basic calculation methods for determining gas outputs from each coal seam can be illustrated by establishing a physical model.

The calculation method used here for each coal seam within a single well containing multiple units is shown in Fig. 1. Thus, assuming that the wellbore penetrates $n$ coal beds, 1\#Coal Bed is used here as an example to illustrate gas output calculation.

Symbol $A$ in Fig. 1 for 1\#Coal Bed denotes well hole cross-sectional area, while $S_{1}$ denotes total gas-phase cross-

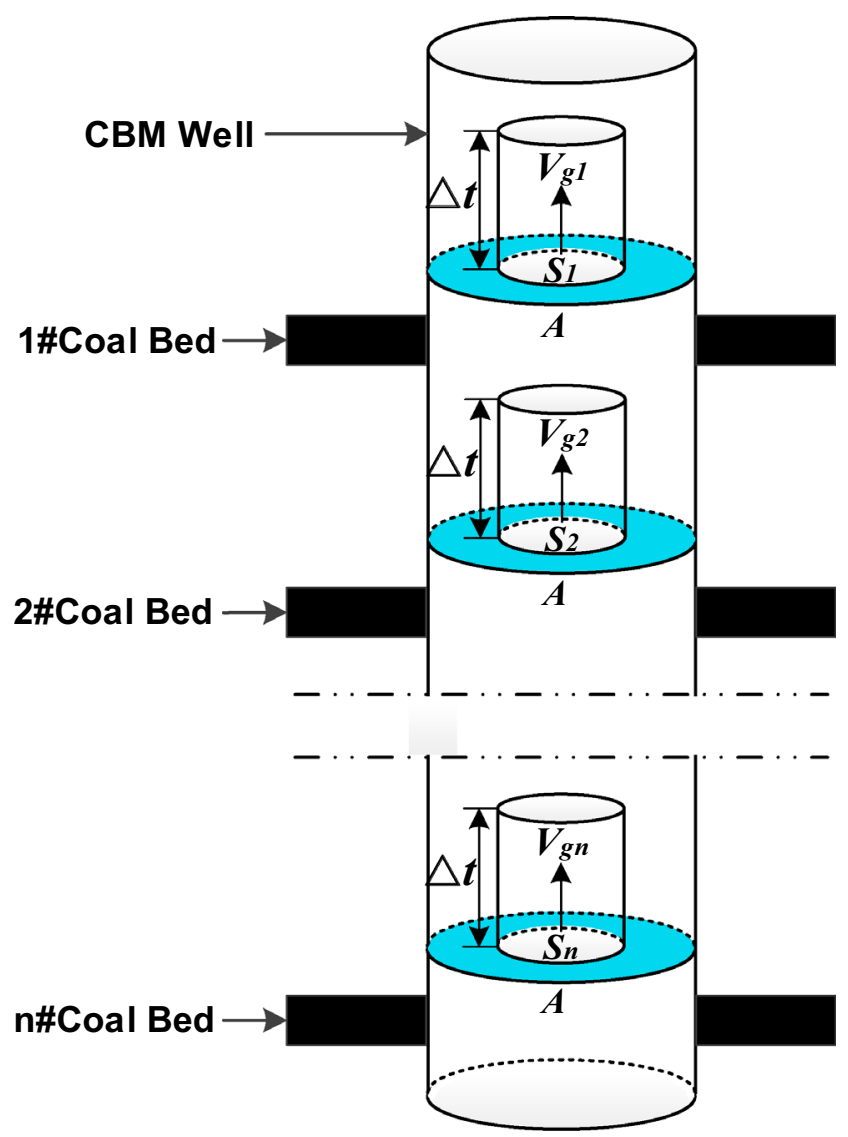

Fig. 1 Method used for calculating gas output from a single wellbore containing multiple coal seams sectional area, and $V_{g 1}$ stands for the gas-phase flow velocity. Thus, when $\Delta t$ is infinitesimal, it can be assumed that $V_{g 1}$ is invariant within $\Delta t$. This means that gas volume $Q$ passing through the cross-sectional area $A$ in $\Delta t$ is as follows:

$Q=S_{1} \Delta t V_{g 1}$

Thus, assuming that the cross-sectional gas fraction is $\varphi_{1}$, the definition of gas fraction can be used to derive:

$S_{1}=A \varphi_{1}$

This means that $Q$ can be obtained according to Eqs. (1) and (2), as follows:

$Q=A \varphi_{1} \Delta t V_{g 1}$

The total gas output of $1 \#$ Coal Bed between $t_{1}$ and $t_{2}$ is $Q_{1}$, as follows:

$Q_{1}=\int_{\mathrm{t}_{1}}^{t_{2}} Q \mathrm{~d} t=\int_{\mathrm{t}_{1}}^{t_{2}} A \varphi_{1} V_{g 1} \mathrm{~d} t$

This relationship means that the total gas output $Q_{n}$ of $n \#$ Coal Bed between $t_{1}$ and $t_{2}$ is as follows:

$Q_{n}=\int_{t_{1}}^{t_{2}} A \varphi_{n} V_{g n} \mathrm{~d} t$

In this relationship, $n$ denotes the coal bed number, as follows:

$n \in N+$

These relationships mean that total gas output, $Q_{t}$, of the CBM well between $t_{1}$ and $t_{2}$ can be expressed as follows:

$$
\begin{aligned}
Q_{\mathrm{t}} & =Q_{1}+Q_{2}+\cdots+Q_{n} \\
& =A \sum_{n=1}^{+\infty} \int_{t_{1}}^{t_{2}}\left(\varphi_{1} v_{g 1}+\varphi_{2} v_{g 2}+\cdots+\varphi_{n} v_{g n}\right) \mathrm{d} t
\end{aligned}
$$

\subsection{Cross-sectional gas fraction}

The calculation parameters contained within Eq. (5) include $\varphi_{n}, A$, and $V_{g \mathrm{n}}$. In this relationship, $\varphi_{n}$ is unknown and $A$ is constant; $V_{g n}$ can be measured and obtained using a specifically designed bubble sensor while $\varphi_{n}$ cannot. This latter variable can be calculated by using a formula derived from other measurement parameters as $\varphi$ is used to denote the cross-sectional gas fraction.

This variable, cross-sectional gas fraction, can be calculated using various numerical methods as well as the split phase flow model method (Chen et al. 2015).

In this approach, assuming that gas-liquid two-phase media move along a pipe at average speeds, a one-dimensional two-speed model can be established so that actual gas-phase velocity is defined as follows: 
$v_{g}=\frac{Q_{g}}{A_{g}}$

In this expression, $v_{g}$ denotes the gas-phase flow velocity, $Q_{g}$ is the gas volume within a given time unit, and $A_{g}$ is the area that the gas phase covers on the flow cross section.

This means that the velocity of the mixture is as follows:

$v=\frac{q_{v g}+q_{v l}}{A}=v_{o g}+v_{o l}$

In this expression, $v$ denotes the velocity of the mixture, $q_{v g}$ is the volume flow rate of the gas phase, $q_{v l}$ is the volume flow rate of the liquid phase, $A$ is cross-sectional area, $v_{o g}$ is the commuted velocity of the gas phase, and $v_{o l}$ is liquid superficial velocity.

As liquid phase flow velocity is very slow or static under CBM drainage and extraction well operating conditions, liquid phase flow velocity can be assumed to be zero and Eq. (9) can be simplified as follows:

$v=v_{o g}$

In this expression, the gas phase drifting flow rate $J_{g}$ is expressed as follows:

$J_{\mathrm{g}}=\frac{A_{g} v_{e g}}{A}=\varphi\left(v_{g}-v\right)=\left(v_{g}-v_{o g}\right)$

In this expression, $J_{g}$ denotes the gas phase drifting flow rate, $v_{e g}$ is the gas phase drifting flow velocity, and $\varphi$ is cross-sectional gas fraction.

Similarly, Eq. (12) can be obtained by combining Eqs. (10) and (11), as follows:

$v_{e g}=v_{g}-v$

Applying the relationship between gas phase drifting flow rate and the freely upward-floating terminal velocity of a single bubble in an interface-free liquid, the following relationship is obtained:

$J_{g}=\varphi(1-\varphi)^{k} v_{B}$

In this expression, $v_{B}$ denotes the terminal velocity of a single bubble in an interface-free liquid while $k$ is both an index and a constant.

The equation for cross-sectional gas fraction can therefore be obtained by combining Eqs. (11), (12), and (13), as follows:

$\varphi=1-\sqrt[\mathrm{m}]{\frac{v_{g}-v_{o g}}{v_{B}}}$

In this expression, the index $m$ and the freely upwardfloating terminal velocity $v_{B}$ rely on flow conditions (Table 1).

The data presented in Table 1 show that $r$ denotes the radius of a bubble, $R_{e}$ is the Reynolds number, $G_{a}$ is the
Table 1 Expressions and terminal velocity indices for free upwardfloating bubbles

\begin{tabular}{lll}
\hline Range & $v_{B}$ & $i$ \\
\hline$R_{e}<2$ & $\frac{2 g\left(\rho_{l}-\rho_{g}\right) r^{2}}{9 \mu_{l}}$ & 2 \\
$2<R_{e}<4 G_{a}^{-2.2}$ & $0.33 g^{0.78}\left(\frac{\rho_{l}}{\mu_{l}}\right)^{0.52} r^{1.28}$ & 1.75 \\
$4 G_{a}^{-2.2}<R_{e}<3 G_{a}^{-2.5}$ & $1.35\left[\frac{\sigma}{\left(\rho_{l}-\rho_{g}\right) r}\right]^{0.5}$ & $1.5-2$ \\
$3 G_{a}^{-2.5}<R_{e}$ & $1.5\left[\frac{\sigma g\left(\rho_{l}-\rho_{g}\right)}{\rho_{l}}\right]^{0.25}$ & $1.5-2$ \\
$2\left[\frac{\sigma}{g\left(\rho_{l}-\rho_{g}\right)}\right]^{0.5}<R_{e}$ & {$\left[\frac{g\left(\rho_{l}-\rho_{g}\right) r}{\rho_{l}}\right]^{0.5}$} & 0 \\
\hline
\end{tabular}

Galileo number, $\rho_{l}$ denotes water density, $\rho_{g}$ denotes gas density, $\mu_{l}$ is dynamic liquid viscosity, and $\sigma$ is the surface tension between gas and liquid, expressed as follows:

$R_{e}=\frac{2 \rho_{l} v_{B} r}{\mu} ;$ and $G_{a}=\frac{g\left(\rho_{l}-\rho_{g}\right) \mu 4}{\rho_{l}^{2} \sigma^{3}}$

This expression refers to the commuted velocity of the gas phase (16), as follows:

$v_{o g}=\frac{q_{v g}}{A}=\varphi \frac{q_{v g}}{A_{g}}=\varphi v_{g}$

Equation (17) can be obtained by combining expressions (14) and (16):

$\varphi=1-\sqrt[i]{\frac{v_{g}(1-\varphi)}{v_{B}}}$

In this expression, $v_{g}$ denotes a specific flow value measured by a flow sensor. Solutions for $i$ and $v_{B}$, which therefore be obtained based on values of $R_{e}$ and $G_{a}$; these values can also be calculated using average values for the collected bubble radius, $r$, as well as related liquid parameter values. These values for $R_{e}$ and $G_{a}$ define calculation range.

An iterative method can then be used to calculate crosssectional gas fraction. The gas outputs of each coal seam as well as a total value can therefore be obtained by substituting cross-sectional gas fraction and related parameters into Eqs. (5-7).

Computer software is necessary to complete these computations because of their complexity and the large calculation memory volumes required.

\section{Measurement system}

A range of different measurement parameters can be defined based on the established gas output calculation model described in this study. This means that a measuring 
device can be designed to capture gas output calculation parameters in real time.

\subsection{Measurement parameters}

Combining the gas output theoretical calculation model presented here with actual operating conditions, parameters can be defined as bubble diameter, gas phase velocity, temperature, and pressure.

On the basis of Eq. (17), necessary measurement parameters are gas-phase flow velocity and bubble radius. However, it is clear that bubble volume will vary if either pressure or temperature changes in the surrounding environment; this relationship is illustrated by the ideal gas state Eq. (18). This means that directly calculated values for coal bed gas output are not comparable with one another if pressure and temperature changes are not also taken into account. Values for these variables should also be recorded, as follows:

$P V=n_{1} R T$

In this expression, $P$ denotes gas pressure while $V$ is gas volume, $n_{1}$ is substance amount, $R$ is the ideal gas constant, and $T$ is absolute temperature.

It is clear that in order to calculate actual gas output from each coal seam, bubble diameter, gas-phase flow velocity, temperature, and pressure must be measured in real-time.

\subsection{Measuring device schematic}

The measuring device used here was designed based on relevant parameter types as well as specific operating environment requirements. The data collected by this device were then transmitted to the ground through a cable in real time for storage and other subsequent operations.

A schematic of the measuring device used in this study is presented in Fig. 2. This device is comprised of a group of sensors, a detection probe, and a ground terminal (Fig. 2). The first group comprises a sensor used to measure bubble diameter and gas-phase flow velocity, as well as one used to measure temperature, and one used to measure pressure.

In each case, a detection probe was installed alongside a specific sensor group. This means that each probe installed above a coal seam is able to collect bubble diameter, gasphase flow velocity, temperature, and pressure data from each coal seam. These data are then transmitted to a ground terminal via a cable in real time for storage and display. Gas outputs from each coal seam can then be obtained via calculations using software by assembling equations and using collected data as parameters in each case.

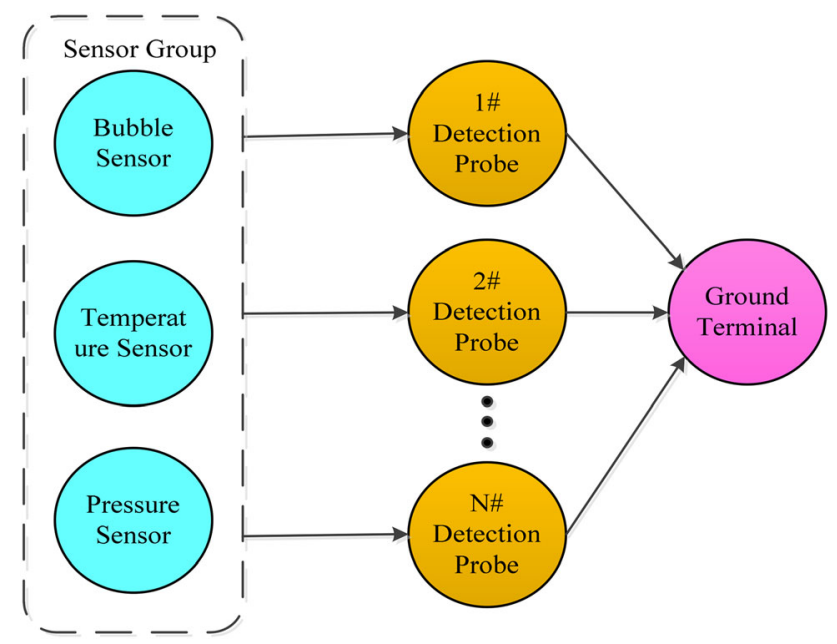

Fig. 2 Measuring device schematic

Sensor installation requirements and actual field conditions mean that a three-dimensional (3D) structural diagram of the detection probe can be generated (Fig. 3). A number of grooves of different sizes are present on this probe which are used for installing a data acquisition circuit as well as the sensor group. Sensor output signal lines are then connected to the data acquisition circuit via these wiring grooves and screw threads are present on both ends of each probe. Detection probes were then installed above each coal bed after connecting screw threads with the CBM extraction well pipeline and calculating necessary length as well as bed depths.

\section{Tests}

The dynamic evaluation technique proposed here to assess gas output from each coal seam was then further verified when a series of laboratory and field experimental tests were performed. Laboratory tests were used mainly to test measurement accuracy and reliability while field tests were used to test both reliability and environmental adaptability.

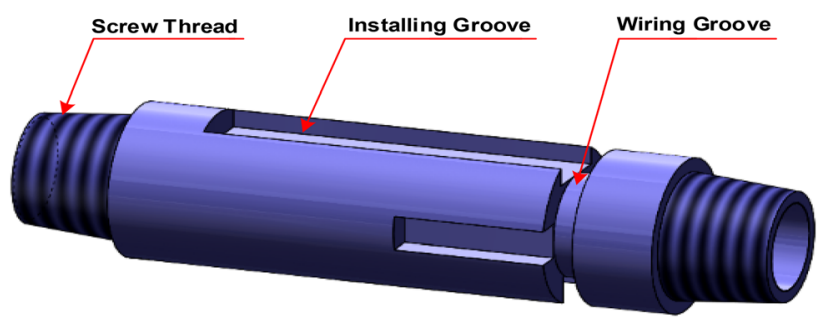

Fig. 3 Detection problem 3D structural diagram 


\subsection{Laboratory tests}

A series of laboratory tests were performed in this study using a CBM extraction well simulator; results show less than $15 \%$ calculation error in each case.

\subsubsection{Test device}

The laboratory tests performed here were all carried out using a customized and standard CBM extraction well simulator. This simulator uses a series of mechanical devices to control flow rate as water and gas enter the wellbore to model two-phase CBM flow. The top of the simulator is fitted with a sealing strip so that wellbore pressure can be applied to model different coal seam depths.

This laboratory simulator can also be used to model various CBM extraction operating conditions in the well, including a two-phase flow model for velocity including gas phase as well as temperature. As the simulator is also equipped with a test system, it is capable of measuring and displaying these parameters in real time (Fig. 4).

\subsubsection{Test procedure}

The following procedure was used for the tests reported here:

(1) The specially designed detection probe was connected with the wellbore lab simulator via a screw thread;

(2) The laboratory simulator beings to work after the power is turned on;

(3) Operation parameters of the laboratory simulator are adjusted one-by-one to enable it to run under a range of different operating conditions including two-

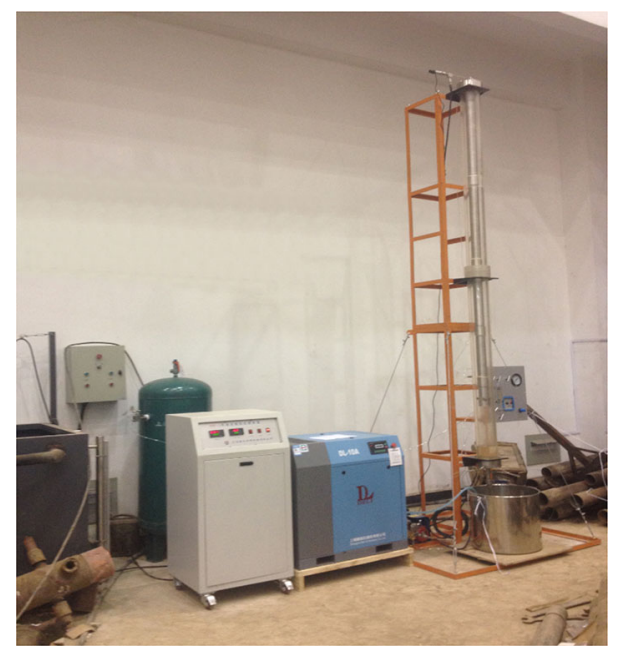

Fig. 4 The CBM well extraction simulator phase and gas-phase flow velocities as well as variable pressure and temperature;

(4) The power supply of the detection probe is turned on in order to collect and store data;

(5) Once data has been collected within a certain time period, power supplies are turned off and data on the meter of the simulator are recorded including the total volume of gas (the standard gas output) entering the simulator within a given time period;

(6) Collected data is input into compiled software and total gas volume (measured gas output) is calculated using software calculation;

(7) Steps (3) to (6) are then repeated to generate several data groups, and;

(8) Power supplies are turned off to end the experiments.

\subsubsection{Test results}

Large volumes of experimental data were collected (Table 2). Results show that when standard gas output is $2.976 \mathrm{~m}^{3}$ (Table 2), two-phase flow and gas-phase velocities measured by the testing device can be measured and reported (Figs. 5 and 6). Analysis of numerous laboratory tests (Table 2) reveals a less than $15 \%$ total error for this proposed dynamic evaluation technique.

Analysis of data presented in Figs. 5 and 6 shows that recovered values for two-phase and gas-phase velocities are similar. The reason for this is that the flow pattern during this period mainly comprised either annular or narrow-beam annular flows; under these conditions, almost no liquid phase is present in the wellbore and so two phase values are similar.

\subsection{Field tests}

A series of field tests were performed based on laboratory results. Field test results show that measurement error using this technique is also limited to below $15 \%$ and so this approach can also be used to judge the main gas-producing coal bed. High detection probe reliability also meets the requirements of field operating conditions.

\subsubsection{Test site}

The field test well used for this analysis was the JS-064 Well operated by the Lanyan CBM Company. This well is located to the north of the town of Jiafeng in Qinshui County, Jincheng City, within Shanxi Province China. This site is about $50 \mathrm{~km}$ from Qinshui County to the northwest and about $50 \mathrm{~km}$ from Jincheng City to the southeast. 
Table 2 Summary of laboratory test data

\begin{tabular}{llrr}
\hline Number & Standard gas output $\left(\mathrm{m}^{3}\right)$ & Measured gas output $\left(\mathrm{m}^{3}\right)$ & Error $(\%)$ \\
\hline 1 & 0.092 & 0.105 & 14.13 \\
2 & 1.771 & 1.967 & 11.07 \\
3 & 2.328 & 2.214 & 4.90 \\
4 & 2.976 & 2.565 & 13.81 \\
5 & 3.517 & 3.281 & 6.71 \\
6 & 4.041 & 4.382 & 8.44 \\
7 & 4.793 & 4.250 & 11.33 \\
8 & 5.177 & 4.511 & 12.86 \\
9 & 5.530 & 5.961 & 7.79 \\
10 & 6.039 & 6.780 & 12.27 \\
11 & 6.701 & 5.904 & 11.89 \\
\hline
\end{tabular}

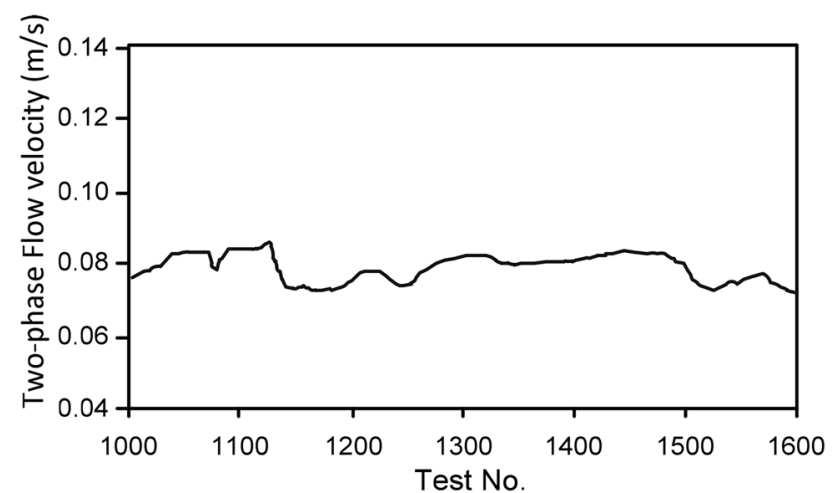

Fig. 5 Two-phase flow velocity when standard gas output is $2.976 \mathrm{~m}^{3}$

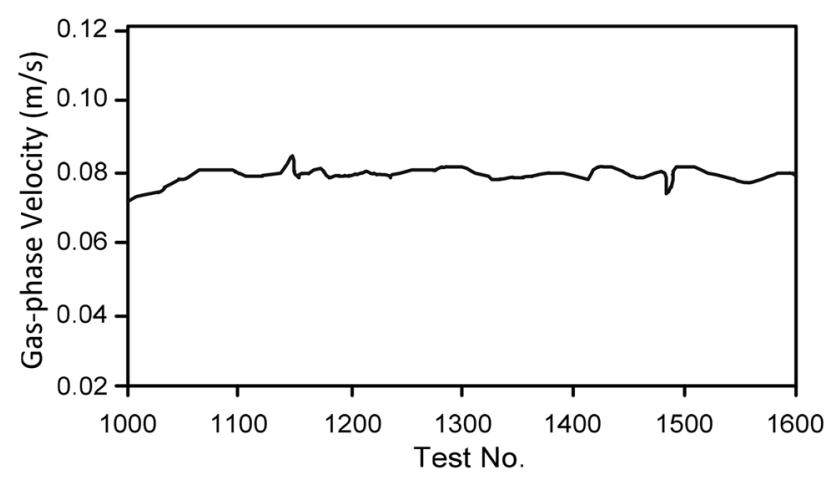

Fig. 6 Gas-phase velocity when standard gas output is $2.976 \mathrm{~m}^{3}$

\subsubsection{Coal bed test well profiles}

The dominant minable coal beds within this region are 9\#Coal Bed and 15\#Coal Bed. Specifically, 15\#Coal Bed is a stable minable bed while 9\#Coal Bed is a partially minable bed. The burial depths and spacing of these two coal beds are shown in Table 3.

\subsubsection{Test preparation}

On the basis of field situations, pipeline lengths, and operating conditions, two data detection probes were installed for this analysis above 9\#Coal Bed and 15\#Coal Bed. The sampling frequency of the detection probe was set to $400 \mathrm{~Hz}$ and the system can continuously store $30 \mathrm{~h}$ of data. The specific installation locations of detection probes are discussed below.

\section{(1) 1\#Detection Probe}

1\#Detection Probe was installed above 9\#Coal Bed at a depth of $378.09 \mathrm{~m}$. This probe was $1.73 \mathrm{~m}$ away from the roof of $9 \#$ Coal Bed.

\section{(2) 2\#Detection Probe}

2\#Detection Probe was installed above 15\#Coal Bed at a depth of $408.02 \mathrm{~m}$. This problem was $9.71 \mathrm{~m}$ away from the roof of $15 \#$ Coal Bed.

The detection probe was installed at the position shown in Fig. 7 based on related information including structure and the depths of coal beds and wells.

\subsubsection{Test processes}

The test procedure used in this analysis was as follows:

(1) Operating preparations were made including moving all equipment and construction tools;

(2) The original well pumping rod was removed and the sand surface was detected using a pump. Sand bailing was then conducted if the distance between the surface and the lowest fracture coal bed floor was less than $20 \mathrm{~m}$;

(3) The original well production pipe string was removed; 
Table 3 Burial depths and spacing of 9\#coal bed and 15\#coal bed

\begin{tabular}{llll}
\hline No. of coal bed & Depth $(\mathrm{m})$ & Thickness $(\mathrm{m})$ & Space between coal beds $(\mathrm{m})$ \\
\hline 9 & $379.82-380.81$ & 0.9 & 36.92 \\
15 & $417.73-420.46$ & 2.73 & \\
\hline
\end{tabular}

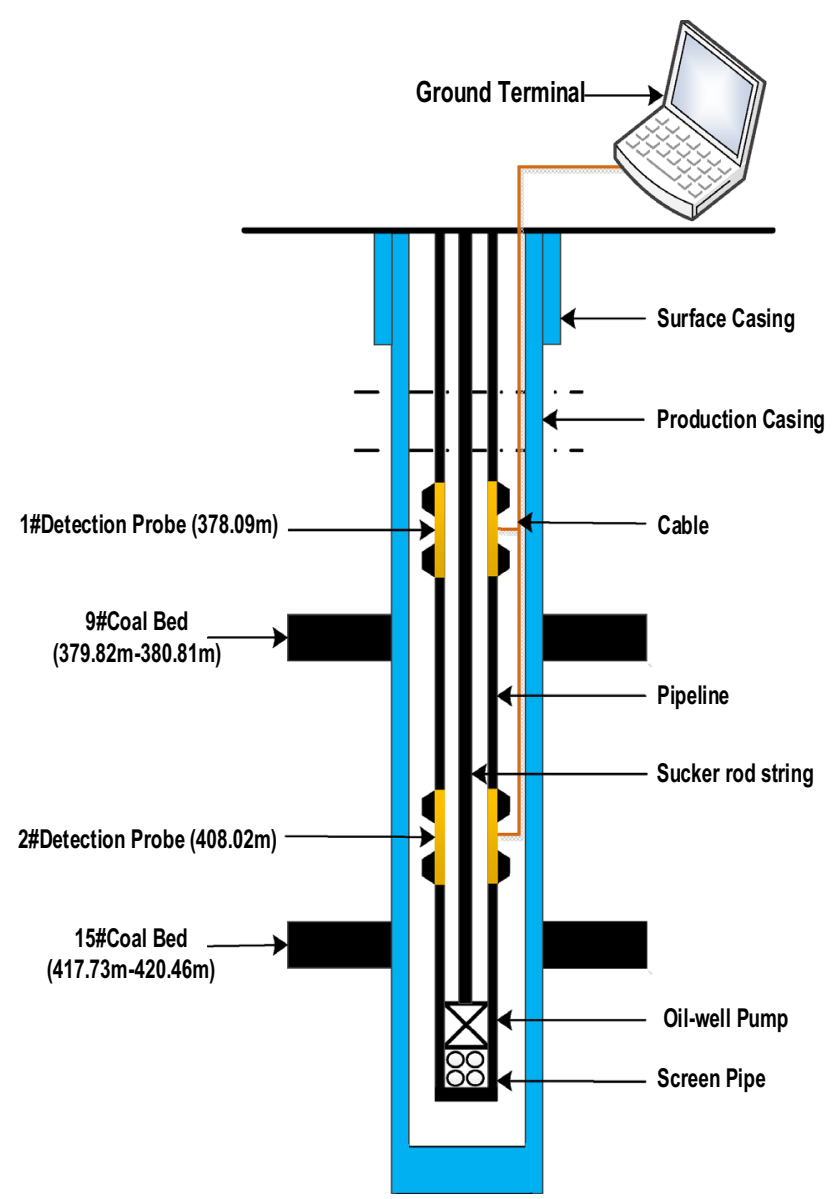

Fig. 7 Detection probe installation position

(4) A corresponding hole scraper was used if necessary;

(5) The pipeline screw thread was checked, the line was measured and the detection probe was deployed accordingly. The field situation of the detection probe within a well is shown in Fig. 8;

(6) The pumping rod screw thread was checked, the pumping pipeline was measured and then lowered according to design requirements;

(7) The field power supply was activated and pumping trials were carried out until the system worked normally;

(8) Field instruments were connected and were checked to determine normal operation with the power supply activated;

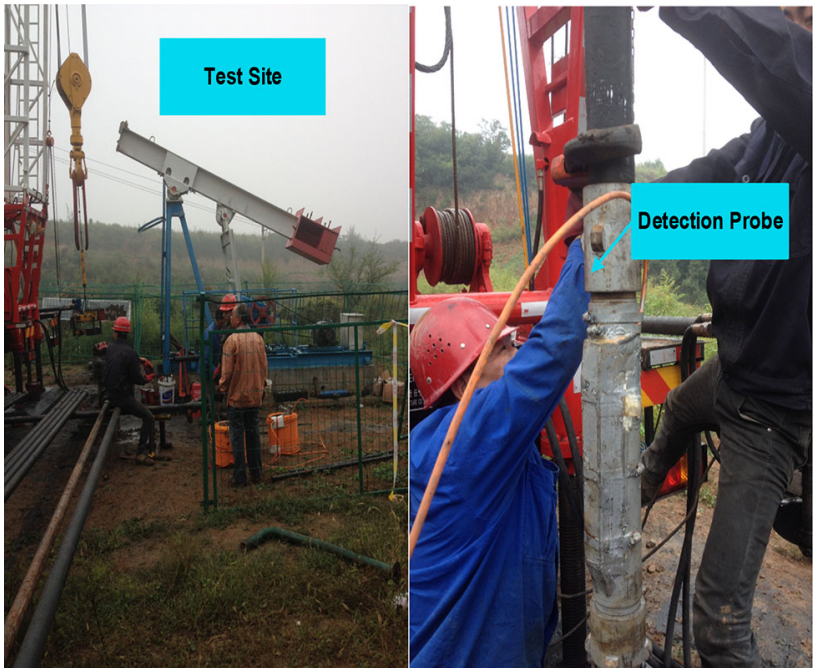

Fig. 8 Field photographs to show the detection probe entering a well

(9) The detection probe power supply was activated and data from the well were transmitted to the ground terminal via a cable in real time, and;

(10) Data stored in the ground terminal were read and processed by the software.

\subsubsection{Test time}

The power supply was turned on to collect data on September $11^{\text {th }}, 2015$, and was turned off to cease data collection on June $28^{\text {th }}, 2016$.

\subsubsection{Test environment}

Measured downhole temperature varied between $5{ }^{\circ} \mathrm{C}$ and $53{ }^{\circ} \mathrm{C}$ while downhole pressure varied between zero and 10.3 MPa over nearly nine months of non-stop tests.

\subsubsection{Results}

The nine months of non-stop data collection reported here mean that the high reliability of the detection probe can be verified, satisfying the requirements of field operating conditions.

(1) Comparative precision analysis 
The data presented in Fig. 7 show that 15\#Coal Bed gas output can be obtained by calculations based on measurements from 2\#Detection Probe. The total gas output of 9\#Coal Bed and 15\#Coal Bed (i.e., total well gas output) can therefore be obtained by calculations based on data measured by 1\#Detection Probe. This reading, termed the standard gas output, from the wellhead instrument is therefore the total well gas output. Throughout the comparative analysis to assess measured field data, only total gas output data was analyzed; this means that just results calculated based on measurements from 1\#Detection Probe (measured gas output) alongside total gas output read by the standard instrument at the wellhead were compared. The unit of standard gas output measured by the field flowmeter is $\mathrm{m}^{3} / \mathrm{d}$; in order to make comparative analysis results more meaningful, measured gas output units were converted to $\mathrm{m}^{3} / \mathrm{d}$. A sample of field data results are presented in Table 4.

Analysis of numerous laboratory tests as well as the data presented in Table 4 show that the error associated with this dynamic evaluation technique is less than $15 \%$.

(2) The main gas-producing coal bed and trend predictions for coal seams

Calculations based on data from 1\#Detection Probe minus data from 2\#Detection Probe equate to the gas output of 9\#Coal Bed. Outputs from 9\#Coal Bed, 15\#Coal Bed and a single well throughout a continuous time period are shown in Fig. 9; in this plot, the abscissa represents time with days as units while ordinate represents gas output in $\mathrm{m}^{3}$ units.

A number of clear conclusions can be drawn based on the data presented in Fig. 9.

(1) The gas output of $15 \#$ Coal Bed is much larger than that of 9\#Coal Bed. This result means that 15\#Coal Bed must be considered the main gas-producing unit throughout this period. Further, subsequent to analyzing coal bed thicknesses, 15\#Coal Bed measures

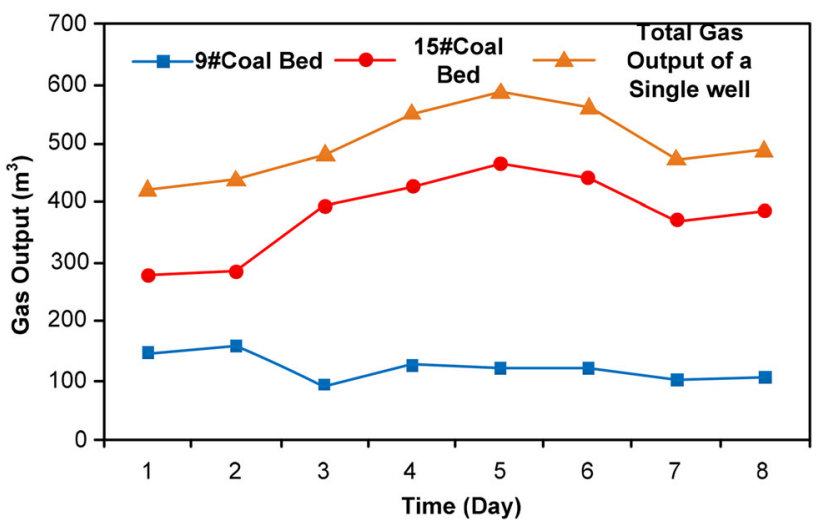

Fig. 9 Gas outputs from different coal seams

$2.73 \mathrm{~m}$ while 9\#Coal Bed measures just $0.9 \mathrm{~m}$; clearly then, the thickness of 9\#Coal Bed is far smaller than that of $15 \#$ Coal Bed. This means that if gas drainage and extraction processes are reasonable and coal bed conditions remain stable, the gas output of $15 \#$ Coal Bed should theoretically be larger than that of 9\#Coal Bed.

(2) The gas output from 15\#Coal Bed fluctuates greatly and tends to rise after eight days. In contrast, the gas output from 9\#Coal Bed fluctuates slightly but tends to be steady or rise slowly after eight days. It can therefore be predicted that $15 \#$ Coal Bed will remain the main gas-producing unit over the foreseeable short period of time.

(3) The total gas output of a single well fluctuates greatly, but tends to increase after eight days. This provides clear evidence that the total gas output of a single well will tend to increase in subsequent days.

(3) Analysis of unit-thickness gas output from each coal seam

Analysis of the data presented in Fig. 9 shows that the gas output from each coal bed is subdivided based on thickness (Fig. 10). Presentation of these data (Fig. 10) includes an abscissa that refers to time with day as the unit

Table 4 Field test data summary

\begin{tabular}{lllr}
\hline Number & Standard gas output $\left(\mathrm{m}^{3} / \mathrm{d}\right)$ & Measured gas output $\left(\mathrm{m}^{3} / \mathrm{d}\right)$ & Error $(\%)$ \\
\hline 1 & 467.127 & 527.256 & 12.87 \\
2 & 554.868 & 598.092 & 7.79 \\
3 & 535.875 & 455.551 & 14.99 \\
4 & 651.278 & 742.352 & 13.98 \\
5 & 485.771 & 428.020 & 11.89 \\
6 & 502.450 & 546.927 & 8.85 \\
7 & 538.331 & 578.010 & 7.37 \\
8 & 420.097 & 368.095 & 12.38 \\
\hline
\end{tabular}




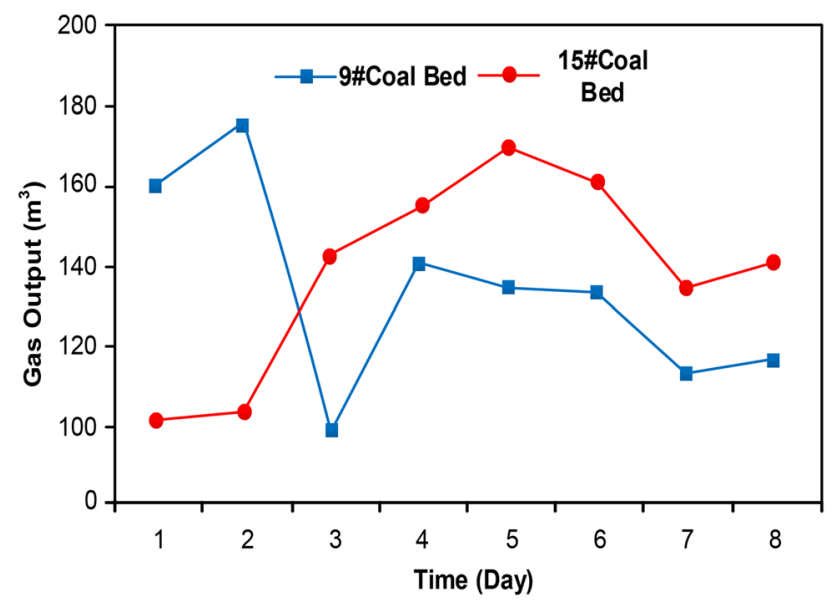

Fig. 10 Unit-thickness gas outputs from different coal seams

as well as an ordinate that refers to the unit-thickness gas output of each coal seam with $\mathrm{m}^{3}$ as the unit.

The data presented in Fig. 10 also reveal that the unitthickness gas output of 9\#Coal Bed is larger than that of 15\#Coal Bed between day one and day two. In contrast, the unit-thickness gas output of 9\#Coal Bed is smaller than that of $15 \#$ Coal Bed between day three and day eight. This phenomenon may be due to changes in extraction processes or in coal bed operating conditions.

\section{Conclusions}

This paper proposes a dynamic evaluation technique to determine coal seam gas outputs during CBM well commingling production. The aim of this approach is to remedy the deficiencies of existing methods for determining the dominant gas-producing coal bed.

The approach proposed here comprises a downhole measurement system combined with a theoretical calculation model. Real-time measurements of gas output parameters including gas-phase flow rate, temperature, and pressure, from different coal beds can be realized in this approach via downhole measurements. Thus, by substituting measured parameters into the deduced theoretical calculation model of gas output presented here, the output of each coal seam can be determined. This approach also means that the dominant gas-producing coal seam within an area can be determined. Numerous laboratory and field tests were performed once the basis of this technique had been developed. The results of this analysis show that:

(1) This technique can be used to effectively evaluate the dominant gas-producing coal bed and that it also conforms to field operating requirements;
(2) The high reliability of the detection device used in this approach means that this technique can be used in poor field operating conditions;

(3) The total gas output of a single well, the gas output of each coal seam, and the unit-thickness gas output of each coal seam can be calculated using this technique. The measurement error of gas output from each coal seam is also limited to less than $15 \%$ when this approach is used;

(4) Trends in gas output from a single well as well as those from each coal seam can be predicted using this technique, and;

(5) Although interlayer interference can be preliminarily solved by installing multiple downhole detection probes, this approach remains insufficient. The model proposed here should be further improved over time to reduce the effects of interlayer interference.

Acknowledgements This research was funded by grants from the Natural Science Foundation in Hubei (2018CFB349) and the National Natural Sciences Foundation of China (41672155, 61733016). Open Research Fund Program of Key Laboratory of Tectonics and Petroleum Resources Ministry of Education (No. TPR-2018-10).

Open Access This article is licensed under a Creative Commons Attribution 4.0 International License, which permits use, sharing, adaptation, distribution and reproduction in any medium or format, as long as you give appropriate credit to the original author(s) and the source, provide a link to the Creative Commons licence, and indicate if changes were made. The images or other third party material in this article are included in the article's Creative Commons licence, unless indicated otherwise in a credit line to the material. If material is not included in the article's Creative Commons licence and your intended use is not permitted by statutory regulation or exceeds the permitted use, you will need to obtain permission directly from the copyright holder. To view a copy of this licence, visit http://creativecommons. org/licenses/by/4.0/.

\section{References}

Ali TA, Sheng JJ (2015) Evaluation of the effect of stress-dependent permeability on production performance in shale gas reservoirs. Society of Petroleum Engineers-SPE eastern regional meeting, society of petroleum engineers, Chicago, October 13-15. Society of Petroleum Engineers (SPE), Richardson

Aminossadati SM, Mohammed NM, Shenshad J (2010) Distributed temperature measurements using optical fibre technology in an underground mine environment. Tunn Undergr Space Technol 25(3):220-229

Anna LO (2003) Ground water flow associated with coalbed gas production Ferron Sandstone, east-central Utah. Int J Coal Geol 56(3):69-95

Budenkov GA, Nedzvetskaya OV, Strizhak VA (2003a) Acoustics of the annular space of producing and injection wells. Russ $\mathbf{J}$ Nondestruct 39(8):571-576

Budenkov GA, Pryakhin AV, Strizhak VA (2003b) Device for detecting the liquid level in the annular space. Russ J Nondestruct 39(9):654-656 
Chen SG (2013) The review of intelligent well completion technology. Petrochem Ind Appl 32(11):4-8

Chen QM, Ma ChH, Li HN et al (2009) Research on liquid level measurement based on optical fiber sensor. J Chang Univ Sci Technol (Nat Sci Ed) 32(4):547-549

Chen Ch, Gao PZ, Tan SCh et al (2015) Theoretical calculation of the characteristics of annular flow in a rectangular narrow channel. Ann Nucl Energy 85(12):259-270

Chen Y, Qin Y, Wei C et al (2018) Porosity changes in progressively pulverized anthracite subsamples: implications for the study of closed pore distribution in coals. Fuel 225:612-622

Clarkson CR, Jordan CL, Gierhart RR et al (2007) Production data analysis of CBM wells. SPE Rocky Mt Oil Gas Technol Symp 4:16-18

Glegola MA, Ditmar P, Hanea R et al (2012) History matching timelapse surface-gravity and well-pressure data with ensemble smoother for estimating gasfield aquifer support-A 3D numerical study. SPE J 17(4):966-980

Li S, Tang D, Pan Z et al (2015) Evaluation of coalbed methane potential of different reservoirs in western Guizhou and eastern Yunnan, China. Fuel 139:257-267

Liu HH, Liu ZB, Ding XF (2014) A new oilfield production prediction method based on $\operatorname{GM}(1, n)$. Petrol Sci Technol 32(1):22-28

Liu Z, Liu D, Cai Y et al (2018) The impacts of flow velocity on permeability and porosity of coals by core flooding and nuclear magnetic resonance: implications for coalbed methane production. J Petrol Sci Eng 171:938-950

Ma T, Rutqvist J, Oldenburg CM et al (2017) Fully coupled twophase flow and poromechanics modeling of coalbed methane recovery: impact of geomechanics on production rate. J Nat Gas Sci Eng 45:474-486

McCoy JN, Rowlan OL, Podio A (2009) Acoustic liquid level testing of gas wells. SPE production and operations symposium, April
4-8. European conference gas well deliquification, Oklahoma, Netherlands

Min Q, Hu JG (1997) A model for predicting the production of oil and gas fields. Acta Pet Sin 18(1):63-69

Qin Y, Moore TA, Shen J et al (2018) Resources and geology of coalbed methane in China: a review. Int Geol Rev 60(5-6):777-812

Robertson SK, Pool M, Farrens MJ et al (2002) Automation system case study of coalbed-methane development. SPE 17(2):91-101

Rotramel JM, Bell MJ (2011) A pilot test of continuous bottom hole pressure monitoring for production optimization of coalbed methane in the Raton Basin, Society of Petroleum Engineers, SPE production and operations symposium, Oklahoma, USA, March 27-29. SPE, Oklahoma

Tao S, Chen S, Pan Z (2019a) Current status, challenges, and policy suggestions for coalbed methane industry development in China: a review. Energy Sci Eng 7:1059-1074

Tao S, Pan ZJ, Tang SL et al (2019b) Current status and geological conditions for the applicability of CBM drilling technologies in China: a review. Int J Coal Geol 202:95-108

Wu C, Wen GJ, Han L et al (2016) The development of a gas-liquid two-phase flow sensor applicable to CBM wellbore annulus. Sensors 16(11):1943-1965

Wu C, Ding HF, Han L (2018) The development and test of a sensor for measurement of the working level of gas-liquid two-phase flow in a coalbed methane wellbore annulus. Sensors 18(2):579-598

Zhang Z, Qin Y, Bai J et al (2018a) Hydrogeochemistry characteristics of produced waters from CBM wells in Southern Qinshui Basin and implications for CBM commingled development. J Nat Gas Sci Eng 56:428-443

Zhang BY, Zhang Z, Qin Y et al (2018b) Optimization methods of production layer combination for coalbed methane development in multi-coal seams. Pet Explor Dev 45(2):312-320 